\title{
Establishing Knowledge Management as an Important Factor to Develop Social Capital for Collaborative Networks
}

\author{
Rolando Vargas Vallejos, Janaina Macke, and Kadígia Faccin \\ University of Caxias do Sul, Graduate Program in Business Administration \\ 95070-560 Caxias do Sul, Brazil \\ rvvallej@ucs.br, jmacke@terra.com.br, kadigia@msn.com
}

\begin{abstract}
Collaborative Networked Organizations are being considered a response to the economic market pressures. Some research projects try to identify the key factors that enable the growth and survival of these collaborative networks. One strategy is to create Virtual Organization Breeding Environments in order to prepare organizations and persons to rapidly respond to a collaboration opportunity. In those breeding environments is possible to develop endogenous resources that permit collaborative practices, like social capital. The present paper discusses the importance of Social Capital and its relationship with Knowledge Management for Virtual Organization Breeding Environments. Knowledge is created during the processes of collaborative networks that rarely are documented and reused. Implementing an effective Knowledge Management method will motivate to increase Social Capital. The present work points out that knowledge sharing is important to develop Social Capital in three Brazilian collaborative networks called VIRFEBRAS, APROVALE and APROBELO.
\end{abstract}

Keywords: Collaborative Networked Organization, Virtual Organization Breeding Environment, Social Capital, Knowledge Management.

\section{Introduction}

Collaborative Networked Organizations (CNOs) are considered a key issue for economic growth. CNOs are new organizational forms of collaboration such as Virtual Organizations, Virtual Enterprises, Professional Virtual Communities and other emergent forms of collaboration, which are regarded as the answer to the increasing need of strong adaptability to a constantly changing economic context.

In recent years, many international projects have contributed to this scientific discipline. In one of these international projects, called ECOLEAD, the Virtual Organization (VO) creation process is considered to happen in the context of a VO Breeding Environment (VBE). A VBE is a long-term collaborative network composed of organizations and specialists prepared to collaborate and thus rapidly respond to a collaboration opportunity or necessity. Camarinha-Matos and Afsarmanesh [1] affirm that VBE creation and VO creation are different processes, triggered by different motivations. A VBE is created as a long-term association and 
its members are recruited from the universe of organizations according to certain criteria. According with Romero et al. [2], a VBE is a long-term strategic alliance of organizations aimed at offering the necessary conditions to support the rapid configuration of a VO. For that reason, VBE focuses on creating an adequate environment for the establishment of cooperation agreements, common operation principles, common interoperable infrastructures, common ontologies, and mutual trust among others.

This paper presents a proposal to focus the implementation of Knowledge Management as a strategic action to form and consolidate a VBE. A Knowledge Management method will create an environment to develop Social Capital between the VBE members. That affirmation is the result of two research projects developed by the Social Theory Research Group (TSO) of the University of Caxias do Sul. In both research projects the objective was to analyze the influence of Social Capital in CNOs. One project studied a mould and die CNO called VIRFEBRAS, and the other project studied a Brazilian wine cluster, two CNOs called APROVALE and APROBELO.

\section{Collaborative Networked Organizations}

The concept of networked organizations is not new, but its use has been influenced by changes in politics, economy and society. Some strong arguments may explain the dissemination of the use of the network concept. In an economical perspective, a networked organization may be an answer because of the intense competition caused by a globalized economy [3], [4]. In a political perspective, a networked organization seems to be an answer to the fiscal crisis and to the erosion of the contemporaneous Government supremacy [3].

In the last two decades a special attention has been given to Collaborative Networked Organization (CNO), considered as one of the emergent models of networked organizations. A CNO is constituted by several entities (e.g., organizations and specialists) that are autonomous, geographically distributed, and heterogeneous in terms of their operating environment, culture, social capital, and goals. These entities collaborate to achieve common goals, and their interactions are supported by Information and Communication Technologies. Unlike other networked organizations, in CNOs collaboration is an intentional property that derives from the shared belief that together the network members can achieve goals that would not be possible or would have a higher cost if attempted by them individually [5].

Some examples of CNOs are Virtual Organizations, Virtual Enterprises, and Professional Virtual Communities. Camarinha-Matos and Afsarmanesh [1] state that the Virtual Organization (VO) creation process is considered to happen in the context of a VO Breeding Environment (VBE). For the authors a VBE is a long-term collaborative association that is composed of organizations prepared to collaborate and thus rapidly respond to an opportunity or necessity. VBE creation and VO creation are different processes, triggered by different motivations. A VBE is created as a long-term association and its members belong to the universe of organizations according to certain established criteria. A VO is a temporary organization triggered by a specific business/collaboration opportunity and its members are primarily selected from the VBE. 
Collaborative environments are traditionally established within a geographic region, as industrial districts, with the advantage of having a common business culture and a sense of community, but this restriction may be overcome by VBEs. VBEs incorporate the involvement of geographically distributed organizations, and this assumption overlooks some important obstacles as: How to quickly establish an interoperable collaboration infrastructure? How to build trust among organizations, which is the base for any collaboration? How to develop and agree on the common principles of sharing and working together? [5]. Noticeably, most of these obstacles are related to human behaviour.

A large number of research projects in CNOs are carried out worldwide, and a growing number of practical cases have been reported. CNOs are complex systems, emerging in many forms in different application domains, and require the contribution from multiple disciplines. Camarinha-Matos and Afsarmanesh [6] have raised the need of modelling for understanding, managing, simulating/ predicting the behaviour of CNOs. As a first attempt to reach a comprehensive modelling framework for CNO, the authors propose four dimensions, which are: structural, componential, functional and behavioural.

The structural dimension addresses the CNO composition considering its constituting elements (participants and their relationships), the roles performed by those elements. The componential dimension focuses on the individual tangible/intangible elements in the CNO's network, e.g. the resource composition such as human elements, software and hardware resources, information and knowledge repositories. The functional dimension addresses the execution of timesequenced flows of operations (processes and procedures) related to the operational phase of the CNO's life cycle. The behavioural dimension addresses the principles, policies, and governance rules that drive or constrain the behaviour of the CNO members.

Following the same line of work, Romero and collaborators [2] propose a VBE reference model and its instantiation methodology considering two sub-spaces: endogenous elements (VBE inside) and exogenous interactions (VBE outside). The authors identify the key business processes required to support and facilitate the VBE management activities needed to be performed during the VBE lifecycle, considering VBE fundamental processes and VBE background processes. One of these VBE fundamental processes is "Trust Management", which refers to Social Capital.

\section{Social Capital as a Key Factor for VBE}

Social Capital is a component of the Social Theory that is being considered as a key element for the development of human and economic communities. Social Capital can be understood as a set of informal norms and values, common to the members of a specific group, which allows cooperation among them.

Social Capital produces socio-cultural goods in the form of emotions, feelings and relationships [7]. High levels of Social Capital enable better use of development opportunities, due to increased information flows that facilitate the action [8], [9]. Thus, confidence, stability, durability of relationships and the network density are key elements to high levels of trust and cooperation. These qualities also influence the clarity and visibility of mutual obligations [10], [8]. 


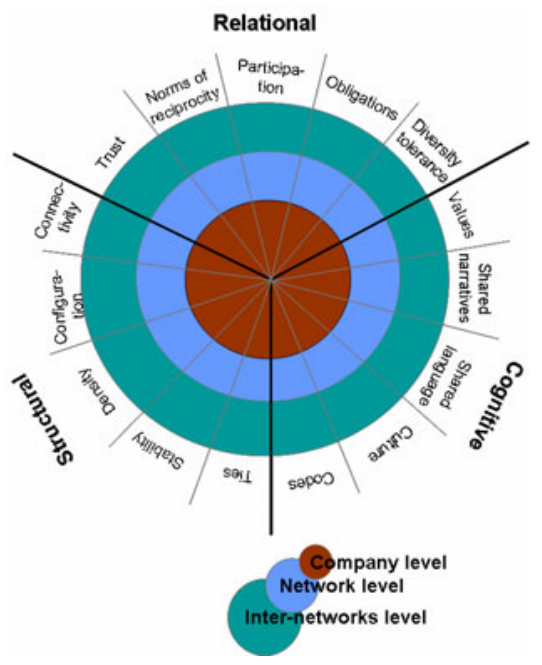

Fig. 1. Social Capital dimensions and their elements [13]

Studying Social Capital and its importance in the creation of intellectual capital, Nahapiet and Ghoshal [11] proposed three Social Capital dimensions, which are: structural, relational and cognitive. The structural dimension analyzes the presence or not of relationships between the actors, the configuration or morphology of the network, describing the standards of connections, through variables as density, connectivity network configuration, stability and ties. The relational dimension describes the kind of personal relationship, developed through a history of interactions [12]. This dimension focuses on aspects that influence behaviour, such as respect and friendship, which are crucial for sociability, acceptance and prestige. Two actors can occupy similar positions in a network, however if their emotional and personal attitudes differ, their actions will be different in many aspects. Therefore it involves a behavioural component, which is revealed through facets as trust and distrust, norms, obligations and expectations, participation and diversity tolerance [10], [11], [9]. The cognitive dimension of Social Capital refers to the resources that emanate shared visions, interpretations and systems of meaning, mainly codes and narratives, shared values and other cultural elements. Figure 1 represents these three Social Capital dimensions and their essential elements.

For Macke and collaborators [13], increasing the Social Capital level in a CNO will facilitate member's access to opportunities, and initiatives for collaborative action. Therefore, Social Capital can be considered the basic resource for a competitive strategy based on cooperation. For the Social Capital flow between organizations, four main conditions are necessary, which are: time, interaction, interdependence and closure [11].

A CNO can be more competitive and have success when investing in two key elements, which are organizational culture and relationship among persons. Elements as trust, networks of relationship and sharing norms are topics that have been discussed by researchers from different areas. The concept became known from Robert Putnam's studies of two decades ago. Putnam relates the results of more than 
twenty years study about Italian society, in which the initial topic was to understand the differences of development of north and south Italy. The author concludes that the disparities between institutional performance and development of the regions result from a major presence of Social Capital. The author's conclusion had a strong impact on the scientific community, and was later corroborated by other studies [9], [14].

\section{Research Projects Evaluating Social Capital in CNOs}

The Social Theory Research Group (TSO) of the University of Caxias do Sul, Brazil developed two research projects analyzing the influence of Social Capital in CNOs. One project studied a mould and die CNO called VIRFEBRAS, and the other studied a Brazilian wine cluster, two CNOs called APROVALE and APROBELO.

In both research projects were developed instruments (surveys) to evaluate the interorganizational Social Capital within a CNO. In order to develop those instruments, in an exploratory phase, semi-structured interviews, direct observation and document analysis of the CNO's members were carried out. Thus, Social Capital elements that influence the dynamics of the network were analyzed, and local aspects related to the network competitiveness, considering the Social Capital classification of Nahapiet and Ghoshal [11] were identified, which are cognitive, relational and structural.

The VIRFEBRAS CNO is a group of small and medium enterprises that work in the mould and die sector. The idea to form the CNO started in 1998, supported by the University of Caxias do Sul, with the objective to join competencies in combination with common goals, keeping the members' own identities, in order to raise more competitiveness and new business opportunities.

The results of the research project were published by Macke and collaborators [13], and one important contribution was the identification and classification of competitive CNOs variables related to the Capital Social dimensions, which is showed in Table 1.

In the second research project, the Serra Gaúcha wine cluster was studied, specifically two CNOs called APROVALE and APROBELO. Although the Serra Gaúcha cluster's production is responsible for $80 \%$ of the national wine production, the Brazilian wine industry is going through some difficulties, and for that reason collaborative networks are being created.

In order to evaluate the inter-organizational Social Capital and its relations with competitiveness of those CNOs, it was applied the survey developed in the first research project. The information was submitted to factor analysis using PCA (Principal Component Analysis), with varimax rotation and pairwise treatment (all valid observations of each variable considered) for the missing data [15].

In the case of the Brazilian wine cluster, the Social Capital is represented mainly by the relational dimension, which explains $25.60 \%$ of the total variance; the structural dimension represents $25.28 \%$ and, the cognitive dimension explains $16.48 \%$ of it [15]. The results show that the Social Capital levels are very similar, ranging from 2.40 to 3.74. Similarly, average factors were close: for the cognitive dimension, 3.37; for the structural dimension, 3.33, and for the relational one, 3.41. Therefore, we concluded that there is a high level of Social Capital in the APROVALE and APROBELO CNOs, and thus a general balance among the three dimensions. 
Table 1. Inter-Organizational Social Capital items of VIRFEBRAS

\section{Dimension}

\section{Items}

When I need help, I can count on other members of the network.

Within the network you need to be aware that no one takes advantage of the situation.

In the formal activities of the network, I do feel part of a group.

I feel a member of the network.

Similarities between participants facilitate the dynamics of the network.

프 Differences within the group do not affect the network.

The members of the network always seek to work together through ideas, resources and information.

Within the network, the members think and act in accordance with the interests of all.

Most members of the network participate on events proposed (meetings, exhibitions, lectures, seminars, trips, etc.).

Even if my opinion is contrary to that of most of the other members of the network, I feel comfortable to discuss it.

The more different ideas within the network, the better.

If I need some information to take a decision, I know where to find it on the network.

Within the network there are several opportunities to exchange information.

The network is connected to other entities, as other networks of businesses, unions, government agencies, among others.

The network has a hierarchical structure (president, directors and other members).

I have contact with members of the network at least once a week.

I also have contact with members of the network outside formal activities.

I consider the members of the network my friends.

Most members know and agree with the objective of the network.

泀

The objective of the network is also clear to those not participating in the network.

I participate in the network because I agree with the purpose for which it was

created.

The members of the network always share information among themselves.

Based on these results, Macke and collaborators [15] established and measured the relationship between Social Capital level and competitiveness. The Relational Social Capital showed higher correlation with Endogenous Resources Appropriation. This indicates that a better use of local characteristics comes from the existence of ties among network participants. These results confirm the initial thesis that Social Capital is closely linked to competitiveness improvement, and the resource-based view defends that resources clearly provide competitive opportunities and high returns.

Something relevant that appears in both research projects was the relationship between knowledge creation and Social Capital. As detected by Macke and collaborators [15], the continuous and dynamic process of knowledge exchange enhances to increase the level of Social Capital in CNOs. Noticeably, all three dimensions of Social Capital (cognitive, structural and relational) are based on information and knowledge sharing as a mediator for use of resources that generate improvements. This is why we understand that the implementation of a Knowledge 
Management method is one of the most important actions for the success of a CNO. During the different processes of a CNO relevant knowledge is created, especially tacit knowledge. The idea is to transform tacit into explicit knowledge in order to maximize the capitalization and dissemination of it.

\section{Conclusions}

The research projects results support the theoretical foundations that information and knowledge sharing is one of the key benefits of Social Capital, because that information and knowledge sharing contributes to the increase of CNOs' business performance. The knowledge combination contributes to Social Capital creation through incremental or radical changes. We agree with Macke and collaborators [15] when they point out four conditions for the combination and exchange processes: (i) the opportunity to make the combination or exchange; (ii) the worthwhile interactions; (iii) the motivation (receptivity to learning and new knowledge creation); and (iv) the combination capabilities (capacity to combine knowledge and best practices).

Based on the research projects results, we conclude that:

i) developing Social Capital is fundamental for the CNOs success;

ii) in order to have higher levels of Social Capital in CNOs, it is recommended to set up VBEs;

iii) in the CNOs' four dimensions of the framework proposed by CamarinhaMatos and Afsarmanesh [6] (structural, componential, functional and behavioural), the presence of Social Capital is transversal. Observe that most of the examples of the endogenous elements in the four dimensions concern to Knowledge Management (Figure 2). The effectiveness of the $\mathrm{CNO}$ life cycle is going to be powered with Knowledge Management.

For that reason, we conclude that Knowledge Management is an important factor to increase the Social Capital level in CNOs. By increasing the Social Capital in a $\mathrm{VBE}$, the effectiveness of the VO/VE life cycle will be more efficient.

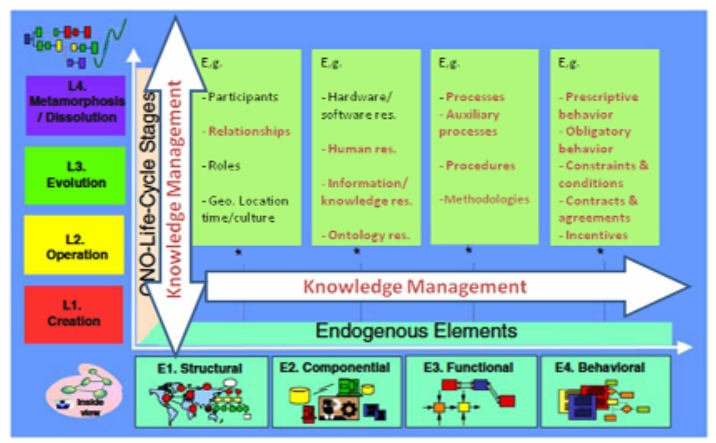

Fig. 2. The presence of Knowledge Management in the proposed framework considering the crossing of $\mathrm{CNO}$ life cycle and the endogenous elements perspective [6] 
Acknowledgments. This work is being supported by the University of Caxias do Sul.

\section{References}

1. Camarinha-Matos, L.M., Afsarmanesh, H.: A framework for virtual organization creation in a breeding environment. Annual Reviews in Control 31(1), 119-135 (2007a)

2. Romero, D., Galeano, N., Molina, A.: A virtual breeding environment reference model and its instantiation methodology. In: Camarinha-Matos, L.M., Picard, W. (eds.) Pervasive Collaborative Networks, vol. 283, pp. 43-52. Springer, Boston (2008)

3. Castells, M.: Aera da informação: economia, sociedade e cultura. Paz e Terra, São Paulo (1998)

4. Loiola, E., Moura, S.: Análise de redes: uma contribuição aos estudos organizacionais. In: Fischer, T. (ed.) Gestão Contemporânea - cidades estratégicas e organizações locais. Fundação Getúlio Vargas, Rio de Janeiro (1996)

5. Camarinha-Matos, L.M., Afsarmanesh, H.: Collaborative Networks: A new scientific discipline. Journal of Intelligent Manufacturing (16), 439-452 (2005)

6. Camarinha-Matos, L.M., Afsarmanesh, H.: A comprehensive modeling framework for collaborative networked organizations. Journal Intelligent Manufacturing 18, 529-542 (2007b)

7. Robison, L., Flora, J.: The social capital paradigm: bridging across disciplines. American Agricultural Economics Association 85(5), 1187-1193 (2003)

8. Coleman, J.S.: Social capital in the creation of human capital. American Journal of Sociology 94, 95-120 (1988)

9. Fukuyama, F.: The great disruption: human nature and the reconstitution of social order. London Profile Books (1999)

10. Putnam, R.D., Leonardi, R., Nanetti, R.Y.: Making democracy work: civic traditions in modern. Princeton University Press, Princeton (1993)

11. Nahapiet, J., Ghoshal, S.: Social capital, intellectual capital and the organizational advantage. Academy of Management Review 23(2), 242-266 (1998)

12. Granovetter, M.S.: The strength of weak ties. American Journal of Sociology 78, 60-80 (1973)

13. Macke, J., Vallejos, R.V., Toss, E.: Building inter-organizational social capital instruments to evaluate collaborative networks. iBusiness 2, 67-71 (2010a)

14. Onyx, J., Bullen, P.: Measuring social capital in five communities. The Journal of Applied Behavioral Science 36(1), 23-42 (2000)

15. Macke, J., Vallejos, R.V., Faccin, K., Genari, D.: The impact of inter-organizational social capital in collaborative networks competitiveness: an empirical analysis. IFIP AICT, vol. 336, pp. 517-526. Springer, Boston (2010b) 